\title{
Ovarian Reserve Diminished by Oral Cyclophosphamide Therapy for Granulomatosis With Polyangiitis (Wegener's)
}

\author{
MEGAN E. B. CLOWSE, ${ }^{1}$ SUSANNAH C. COPLAND, ${ }^{1}$ TSUNG-CHENG HSIEH, ${ }^{1}$ SHEIN-CHUNG CHOW, ${ }^{1}$ \\ GARY S. HOFFMAN, ${ }^{2}$ PETER A. MERKEL, ${ }^{3}$ ROBERT F. SPIERA, ${ }^{4}$ JOHN C. DAVIS, JR., ${ }^{5}$ \\ W. JOSEPH MCCUNE, ${ }^{6}$ STEVEN R. YTTERBERG, ${ }^{7}$ E. WILLIAM ST.CLAIR, ${ }^{1}$ NANCY B. ALLEN, ${ }^{1}$ \\ ULRICH SPECKS, ${ }^{7}$ AND JOHN H. STONE, ${ }^{8}$ FOR THE WGET RESEARCH GROUP
}

Objective. Standard treatment for severe granulomatosis with polyangiitis (Wegener's) (GPA) is daily oral cyclophosphamide (CYC), a cytotoxic agent associated with ovarian failure. In this study, we assessed the rate of diminished ovarian reserve in women with GPA who received CYC versus methotrexate (MTX).

Methods. Patients in the Wegener's Granulomatosis Etanercept Trial received either daily CYC or weekly MTX and were randomized to etanercept or placebo. For all women ages <50 years, plasma samples taken at baseline or early in the study were evaluated against samples taken later in the study to compare levels of anti-Müllerian hormone (AMH) and follicle-stimulating hormone (FSH), endocrine markers of remaining egg supply. Diminished ovarian reserve was defined as an $\mathrm{AMH}$ level of $<1.0 \mathrm{ng} / \mathrm{ml}$.

Results. Of 42 women in this analysis (mean age 35 years), 24 had CYC exposure prior to enrollment and 28 received the drug during the study. At study entry, women with prior CYC exposure had significantly lower AMH, higher FSH, and a higher rate of early menstruation cessation. For women with normal baseline ovarian function, 6 of 8 who received CYC during the trial developed diminished ovarian reserve, compared to 0 of 4 who did not receive CYC $(P<0.05)$. Changes in AMH correlated inversely with cumulative CYC dose $(P<0.01)$, with a $0.74 \mathrm{ng} / \mathrm{ml}$ decline in AMH level for each 10 gm of CYC.

Conclusion. Daily oral CYC, even when administered for less than 6 months, causes diminished ovarian reserve, as indicated by low AMH levels. These data highlight the need for alternative treatments for GPA in women of childbearing age.

\section{Introduction}

Among women treated with cyclophosphamide (CYC), ovarian failure has long been viewed as an unfortunate but

ClinicalTrials.gov identifier: NCT00005007.

Supported by Amgen; a contract with the NIH National Institute of Arthritis and Musculoskeletal and Skin Diseases (N01-AR-9-2240); a grant from the FDA Office of Orphan Products (FD-R-001652-01); General Clinical Research Center grants from the NIH National Center for Research Resources to Johns Hopkins University School of Medicine (M01-RR0-2719), Boston University (M01-RR0-00533), University of Michigan (M01-RR-0042), and Duke University (M01-RR-30); and the Charles Hammond Research Fund of Duke University Medical Center's Department of Obstetrics and Gynecology.

${ }^{1}$ Megan E. B. Clowse, MD, MPH, Susannah C. Copland, MD, Tsung-Cheng Hsieh, MS, Shein-Chung Chow, PhD, E. William St.Clair, MD, Nancy B. Allen, MD: Duke University Medical Center, Durham, North Carolina; ${ }^{2}$ Gary S. Hoffman, MD: Cleveland Clinic Foundation, Cleveland, Ohio; ${ }^{3}$ Peter A. Merkel, MD, MPH: Boston University, Boston, inevitable consequence of therapy. However, with recent successes in ovarian preservation and new alternative therapies for vasculitis, patients with this condition may now be able to avoid this treatment complication. Although the frequency of ovarian failure following CYC therapy in patients with vasculitis has not been previously

Massachusetts; ${ }^{4}$ Robert F. Spiera, MD: Hospital for Special Surgery, New York, New York; ${ }^{5}$ John C. Davis, Jr., MD, MPH: University of California, San Francisco; ${ }^{6} \mathrm{~W}$. Joseph McCune, MD: University of Michigan, Ann Arbor; ${ }^{7}$ Steven R. Ytterberg, MD, Ulrich Specks, MD: Mayo Clinic, Rochester, Minnesota; ${ }^{8}$ John H. Stone, MD, MPH; Massachusetts General Hospital, Boston.

Dr. Allen has received consultant fees, speaking fees, and/or honoraria (less than $\mathbf{\$ 1 0 , 0 0 0 )}$ from Genentech.

Address correspondence to Megan E. B. Clowse, MD, MPH, Box 3535, Trent Drive, Durham, NC 27710. E-mail: megan.clowse@duke.edu.

Submitted for publication April 20, 2011; accepted in revised form August 16, 2011. 


\section{Significance \& Innovations}

- This study demonstrates that even low doses of daily oral cyclophosphamide can have a clinically significant and lasting impact on ovarian reserve in women with vasculitis.

- The effect of cyclophosphamide on ovarian reserve in women with vasculitis had not previously been assessed. The data from systemic lupus erythematosus (SLE) patients treated with cyclophosphamide cannot reliably be applied to patients with vasculitis, given the difference in dosing methods (intermittent intravenous for SLE patients versus daily oral for vasculitis patients).

assessed, reports have suggested that $30-50 \%$ of women receiving intravenous monthly CYC for other indications develop ovarian failure $(1,2)$. We suspected that the rate of ovarian dysfunction might be higher for women receiving daily oral CYC, the standard treatment protocol for vasculitis, as this method of administration exposes the ovary to toxic therapy daily and leads to cumulative doses 2-3fold higher than those resulting from the monthly intravenous doses typically administered for other conditions.

In prior studies, ovarian failure has been determined according to 2 criteria: the cessation of menstruation and elevated levels of follicle-stimulating hormone (FSH). While these measures accurately identify women in menopause, they are less useful for assessing whether a woman has compromised fertility. Even in healthy women, fertility significantly declines in the 2 decades prior to menopause, when menstruation is still active and FSH levels are in the normal range (3). Using only the presence of menses and high FSH levels to evaluate ovarian function therefore underestimates the number of women with ovarian damage that can limit fertility and hasten menopause.

Anti-Müllerian hormone (AMH) is a newer marker that better reflects ovarian reserve and can predict the time to menopause. Produced by small early follicles whose ongoing growth is independent of the menstrual cycle, $\mathrm{AMH}$ by extension reflects the number of primordial follicles that remain in the ovary (4). AMH provides several notable advantages over more traditional measures of ovarian function: 1) exhibiting little fluctuation between or within menstrual cycles, AMH can be measured at any time in the cycle (5); 2) in healthy patients, AMH levels decline slowly with aging, but among women who sustain ovarian injury from chemotherapy or radiation, these levels decline more rapidly (6); 3) on average, a 40-year-old woman will have an $\mathrm{AMH}$ level of $1.0 \mathrm{ng} / \mathrm{ml}$ (7), and as $\mathrm{AMH}$ levels decline below this, conception becomes less likely (but not impossible); and 4) the decline in AMH precedes the rise in FSH and menopause by several years (8).

To our knowledge, this is the first study of $\mathrm{AMH}$ in women with vasculitis. By comparing female vasculitis patients who have undergone CYC therapy with those who have not, we have been able to investigate the impact of this therapy on $\mathrm{AMH}$ and therefore to assess associated subclinical ovarian damage and diminished ovarian reserve.

\section{Patients and Methods}

The Wegener's Granulomatosis Etanercept Trial (WGET) was a randomized, double-blind, placebo-controlled trial of etanercept, a tumor necrosis factor $\alpha$ inhibitor, for the treatment of granulomatosis with polyangiitis (Wegener's) (GPA). The study design and main results have been described in detail in an earlier publication (9).

In addition to receiving twice-weekly subcutaneous injections of etanercept in $25 \mathrm{mg}$ doses or placebo, all of the patients also underwent standard therapy for active GPA. Patients with severe disease received prednisone and daily oral CYC at a dosage of $2 \mathrm{mg} / \mathrm{kg} /$ day, with adjustments for renal insufficiency. Patients who presented with limited disease received prednisone and methotrexate (MTX) in increasing weekly oral doses of up to $25 \mathrm{mg}$. Patients with renal dysfunction received azathioprine instead of MTX. For patients who experienced severe GPA flares during the trial, therapy with CYC and glucocorticoids was initiated. Women were also allowed to take oral contraceptives, depot medroxyprogesterone, or gonadotropin-releasing hormone $(\mathrm{GnRH})$ agonists.

For this subanalysis of the WGET data set, we included all women who were ages $<50$ years at the time of enrollment. Two time points for analysis were included for each qualified patient: the first available plasma sample (taken either at screening or at an early followup visit) and the last available plasma sample. After collection, the plasma samples were delivered to the University of North Carolina Immunotechnologies Core for enzyme-linked immunosorbent assay, where AMH and FSH were measured.

Diminished ovarian reserve was defined as an $\mathrm{AMH}$ level of $<1.0 \mathrm{ng} / \mathrm{ml}$. For purposes of baseline analysis, patients were divided by age: $<18$ years, when AMH tends to be on the increase; 18-35 years, during which years $\mathrm{AMH}$ tends to decline slowly; and >35 years, when AMH is expected to approach $1.0 \mathrm{ng} / \mathrm{ml}$.

FSH is most reliable as a predictor of ovarian function when blood samples are drawn early in the menstrual cycle. In this study, however, blood draws were not timed with menses, which diminished the usefulness of FSH in assessing ovarian sufficiency. In addition, oral contraceptives and $\mathrm{GnRH}$ agonists suppress FSH, so all women receiving these medications were excluded from the $\mathrm{FSH}$ analysis. Menstrual history was only obtained at study entry.

We assessed 4 primary outcomes. First, we compared the proportion of women with diminished ovarian reserve at study entry and completion based on prior CYC exposure. To evaluate the effect of CYC on AMH during the trial, we included only women with a baseline AMH level $>1.0 \mathrm{ng} / \mathrm{ml}$. To determine the dose effect of CYC on AMH, we employed regression analysis, with a $P$ value of less than 0.05 being considered statistically significant. Finally, women were divided by age to assess the role that age at CYC therapy has on ovarian function. 


\begin{tabular}{|c|c|c|c|c|}
\hline & $\begin{array}{l}\text { Women ages } \\
<50 \text { years }\end{array}$ & $\begin{array}{l}\text { No CYC prior to } \\
\text { WGET enrollment (n) }\end{array}$ & $\begin{array}{l}\text { CYC prior to WGET } \\
\text { enrollment (n) }\end{array}$ & $\boldsymbol{P}$ \\
\hline \multicolumn{5}{|c|}{$\begin{array}{c}\text { AMH level at first sample, } \\
\text { mean } \pm \text { SD } \mathrm{ng} / \mathrm{ml}\end{array}$} \\
\hline All patients & $1.4 \pm 2.0$ & $2.5 \pm 2.4(16)$ & $0.6 \pm 1.2(24)$ & 0.002 \\
\hline Age $<18$ years & $1.6 \pm 1.8$ & $0.67(1)$ & $2.0 \pm 2.3(2)$ & NAt \\
\hline Age $18-35$ years & $2.5 \pm 2.4$ & $4.2 \pm 1.9(7)$ & $1.0 \pm 1.7(8)$ & 0.004 \\
\hline Age $\geq 35$ years & $0.6 \pm 1.2$ & $1.1 \pm 1.9(8)$ & $0.3 \pm 0.4(14)$ & 0.14 \\
\hline \multicolumn{5}{|c|}{$\begin{array}{l}\text { Diminished ovarian reserve } \\
\text { (AMH level }<1.0 \mathrm{ng} / \mathrm{ml} \text { ), \% }\end{array}$} \\
\hline All patients & 70 & $50(16)$ & $83(24)$ & 0.03 \\
\hline Age $<18$ years & 67 & $100(1)$ & $50(2)$ & NAt \\
\hline Age $18-35$ years & 40 & $0(7)$ & $75(8)$ & 0.003 \\
\hline Age $\geq 35$ years & 91 & $86(8)$ & $93(14)$ & 0.6 \\
\hline \multicolumn{5}{|c|}{$\begin{array}{c}\text { Premature cessation of } \\
\text { menstruation, \% }\end{array}$} \\
\hline All patients & 21 & $0(16)$ & $33(24)$ & 0.013 \\
\hline Age $<18$ years & 0 & $0(1)$ & $0(2)$ & NAt \\
\hline Age $18-35$ years & 6 & $0(7)$ & $13(8)$ & 0.32 \\
\hline Age $\geq 35$ years & 36 & $0(8)$ & $50(14)$ & 0.015 \\
\hline \multicolumn{5}{|c|}{$\begin{array}{c}\text { Baseline FSH by age group, } \\
\text { mean } \pm \text { SD } \mathrm{mIU} / \mathrm{ml} \neq\end{array}$} \\
\hline All patients & $14.9 \pm 20.9$ & $5.3 \pm 7.6(12)$ & $20.63 \pm 24.2(20)$ & 0.042 \\
\hline Age $<18$ years & 4.4 & $4.4(1)$ & - & NAt \\
\hline Age $18-35$ years & $8.2 \pm 11.1$ & $2.2 \pm 2.0(4)$ & $11.67 \pm 12.9(7)$ & 0.19 \\
\hline Age $\geq 35$ years & $19.1 \pm 24.4$ & $7.2 \pm 9.7(7)$ & $25.45 \pm 27.8(13)$ & 0.11 \\
\hline $\begin{array}{l}{ }^{*} \mathrm{CYC}=\text { cyclophosphe } \\
\mathrm{NA}=\text { not applicable; } \mathrm{F} \\
+ \text { Too few subjects for } \\
\text { \# FSH analysis does } \mathrm{r} \\
\text { agonists. }\end{array}$ & $\begin{array}{l}\text { Wegener's Gra } \\
\text { nulating horm } \\
\text { testing. } \\
\text { en currently t }\end{array}$ & $\begin{array}{l}\text { lomatosis Etanercept Tria } \\
\text { e. } \\
\text { ing oral contraceptives }\end{array}$ & $\begin{array}{l}\mathrm{MH}=\text { anti-Müllerian } \mathrm{h} \\
\text { onadotropin-releasing } \mathrm{h}\end{array}$ & $\begin{array}{l}\text { ormone; } \\
\text { ormone }\end{array}$ \\
\hline
\end{tabular}

\section{Results}

Of the 180 total patients enrolled in the study, 42 were women ages $<50$ years at trial entry. Two of these women were excluded from the analysis of baseline hormone levels, as no sample had been taken for them prior to the administration of CYC during the trial. Therefore, 40 women qualified for the baseline analysis, with a mean \pm SD age of $35.2 \pm 9.2$ years (range $14-46$ years). The majority were white $(86 \%)$, educated beyond high school (64\%), and either employed or in school (64\%).

The patients' baseline AMH concentrations were highly dependent on both age and prior CYC therapy (Table 1). Of 40 patients, $24(60 \%)$ had received CYC prior to the first available hormone sample. For women between ages 18 and 35 years, the mean AMH concentration was 4-fold higher and the rate of diminished ovarian reserve significantly was lower among women who had not received prior CYC $(P<0.01)$. For women ages $>35$ years, a trend toward diminished AMH among those with prior CYC therapy was evident, but not statistically significant. Premature cessation of menstruation occurred predominantly in women ages $>35$ years with prior CYC exposure. FSH was almost 4-fold higher for women with prior CYC exposure, but the differences were not statistically significant based on age.

Only 12 women entered the study with normal ovarian reserve. In this group, those treated with CYC during the WGET experienced a decline in AMH levels significantly greater than that experienced by women who did not receive CYC (Figure 1). The 8 women who received CYC had a mean $\pm \mathrm{SD}$ decline in $\mathrm{AMH}$ from $4.2 \pm 2.3 \mathrm{ng} / \mathrm{ml}$ to $0.6 \pm 0.5 \mathrm{ng} / \mathrm{ml}$. The 4 women who did not receive CYC registered a modest increase in their mean \pm SD AMH concentrations, from $3.3 \pm 1.0 \mathrm{ng} / \mathrm{ml}$ to $4.0 \pm 1.4 \mathrm{ng} / \mathrm{ml}$ $(P<0.005$, comparing the change in women exposed versus not exposed to CYC). Of these 4 women, 3 were adults whose AMH levels remained steady; one young patient's AMH levels rose as she went through puberty. The degree of change in AMH level was predicted by the cumulative dose of CYC administered during the trial (re-

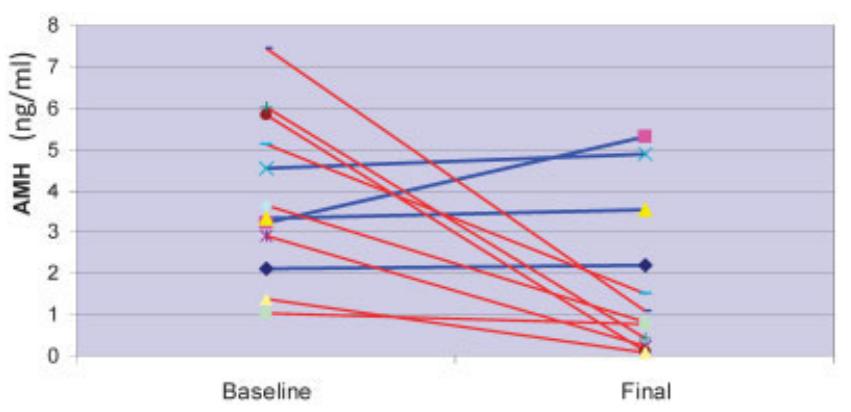

Figure 1. Change in anti-Müllerian hormone (AMH) during the Wegener's Granulomatosis Etanercept Trial (WGET) for women with a baseline AMH level of $>1.0 \mathrm{ng} / \mathrm{ml}$. Red lines show cyclophosphamide (CYC) received during the WGET. Blue lines show those that did not receive CYC during the WGET. 


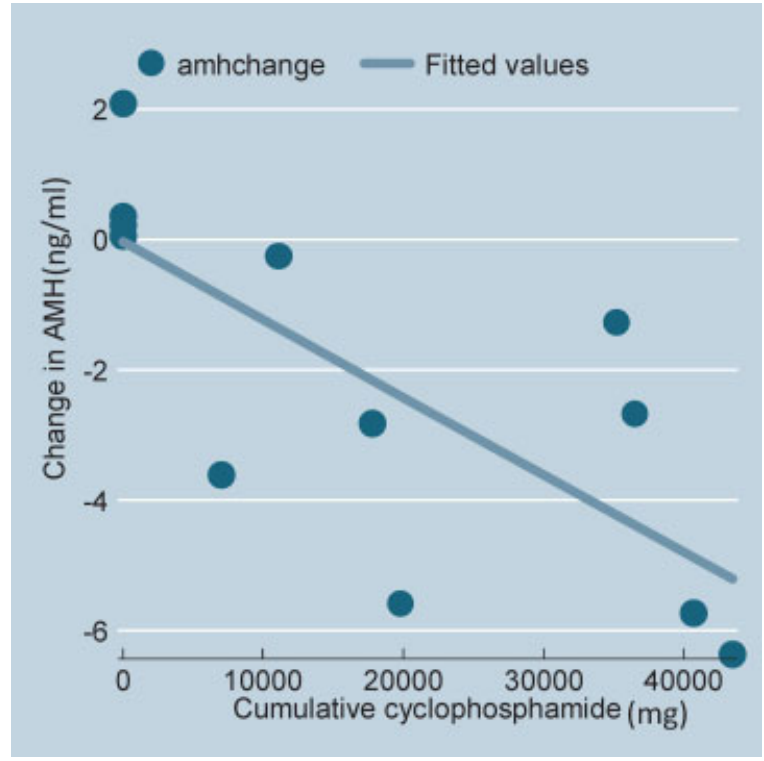

Figure 2. Change in anti-Müllerian hormone (AMH; ng/ml) level by cumulative cyclophosphamide dose (mg) during the Wegener's Granulomatosis Etanercept Trial. This analysis included only women with a baseline AMH level of $>1.0 \mathrm{ng} / \mathrm{ml}$.

gression coefficient $-0.074, P<0.01$ ). For each $10 \mathrm{gm}$ of CYC administered, the AMH level fell, on average, by 0.74 $\mathrm{ng} / \mathrm{ml}$ (Figure 2). Adjusting for age at study entry did not impact the statistical significance of the correlation between cumulative CYC dose and decline in AMH. The AMH level of 2 women increased modestly (by 0.59 and $0.83 \mathrm{ng} / \mathrm{ml}$ ) 3 years after CYC cessation. This study was not powered to identify other risk factors for AMH decline.

Every dose level of CYC appeared to significantly decrease $\mathrm{AMH}$ in this study. Even the 3 women ages $<35$ years who received $<12.5$ gm of CYC prior to study entry had a baseline AMH level lower than expected for their age (range $0.47-1.03 \mathrm{ng} / \mathrm{ml}$ for women ages 23-32 years). Of 10 women ages $<35$ years who received 12.5-25 gm of CYC, only 2 exited the study with AMH levels $>1.0 \mathrm{ng} / \mathrm{ml}$. These data suggest that most, but not all, women treated with a short course of daily oral CYC sustain significant ovarian damage.

\section{Discussion}

This study documents the rapid ovarian damage caused by oral CYC in women ages $<50$ years who undergo treatment for GPA. At baseline, women with prior CYC therapy had significantly lower $\mathrm{AMH}$, higher $\mathrm{FSH}$, and a higher rate of diminished ovarian reserve, and were more likely to have premature cessation of menses. Regardless of their baseline measures, all women ages $<50$ years treated with CYC during the trial experienced a dramatic decrease in $\mathrm{AMH}$. The cumulative dose of CYC was directly correlated to the degree of this decline, but even a low cumulative dose over a short duration was associated with unusually low AMH.

Although previous studies of women with rheumatic disease have likewise documented ovarian failure following treatment with CYC, these studies employed cessation of menses and elevated FSH as the only indicators. Using this definition, an estimated $30 \%$ of women with systemic lupus erythematosus will develop ovarian failure following CYC, with older age and higher cumulative CYC dose as the most important predictors.

Although the average age of women at menopause is 51 years, the average age of last childbirth in societies that do not use contraception is 41 years, which indicates that menstrual bleeding persists for an average of 10 years in the absence of ovarian function capable of producing pregnancy (3). Determining ovarian function based on menses therefore fails to provide sufficient information about fertility.

$\mathrm{AMH}$, a marker of ovarian reserve primarily studied in the reproductive endocrinology literature, has now also gained favor in the chemotherapy literature based on its improved sensitivity profile relative to traditional $\mathrm{FSH}$ testing. In females, $\mathrm{AMH}$ is low at birth, rises during late puberty, then declines with age, becoming undetectable after both natural and surgical menopause (7). Unlike FSH, AMH does not fluctuate significantly throughout the menstrual cycle (5). Moreover, according to numerous observational studies of the effects of chemotherapy, decrements in AMH precede elevations in FSH (10).

Whether AMH levels could rebound to a clinically significant degree over a long period of time following administration of CYC is not known. In this cohort, AMH level was found to have increased by $0.5-0.8 \mathrm{ng} / \mathrm{ml}$ in 2 women with 3 years of post-CYC followup. Anecdotal evidence suggests that women with apparent infertility for years to decades following CYC therapy may eventually conceive naturally. It cannot be determined, however, if this reflects a slow rise in $\mathrm{AMH}$ and ovarian viability, or if it reflects that while egg number is low, individual egg quality can still provide for the fortuitous happenstance that one of the remaining oocytes will be fertilized.

Unfortunately, this study does not provide sufficient data to determine the impact of oral contraceptives or GnRH agonists on ovarian preservation. Most prior studies of oral contraceptives during CYC therapy have not documented a protective effect (11). GnRH agonist cotherapy during CYC treatment, however, has been shown to prevent cessation of menstruation in both rheumatologic and oncologic studies (12). How this protocol might affect fertility or AMH is less clear.

The dramatic decline in ovarian reserve with CYC therapy documented in this study suggests that physicians should consider alternate therapies for young women with vasculitis. Several options exist, including administration of intermittent intravenous rather than daily oral CYC, using the shortest course of CYC possible then switching to a medication that is less toxic to the ovaries, and consideration of rituximab therapy for young women (13). The Rituximab in ANCA (antineutrophil cytoplasmic antibody)-Associated Vasculitis trial recently demonstrated that rituximab may be a viable option for young women who wish to preserve fertility but require treatment of ANCA-associated vasculitis (14). Other avenues for fertility preservation include cotherapy with $\mathrm{GnRH}$ agonists and cryopreservation of the ovary, oocytes, or embryos.

Access to a control group with GPA (although not of similar severity), use of a single ovarian toxic medication, 
and use of $\mathrm{AMH}$ as a marker of subclinical ovarian damage confer particular importance on the results of this study. The primary drawbacks lie in the limited number of women without previous CYC exposure and the fact that this analysis was not planned prior to enrollment in WGET; as a result, blood draws were not timed to the menstrual cycle, therefore making the FSH measurement less useful, and menstrual histories were not taken at the completion of the study. Due to the difference in primary outcome, these lapses have prevented direct comparison of the current study to other investigations of ovarian function in women with rheumatic disease.

Nevertheless, this study strongly suggests that the administration of daily oral CYC for severe GPA results in ovarian damage among women of childbearing age. Efforts to minimize ovarian exposure to CYC may therefore help preserve fertility and delay menopause in women with vasculitis.

\section{AUTHOR CONTRIBUTIONS}

All authors were involved in drafting the article or revising it critically for important intellectual content, and all authors approved the final version to be published. Dr. Clowse had full access to all of the data in the study and takes responsibility for the integrity of the data and the accuracy of the data analysis. Study conception and design. Clowse, Copland, Chow, Hoffman, Merkel, Stone.

Acquisition of data. Clowse, Copland, Hoffman, Merkel, Spiera, Davis, McCune, Ytterberg, St.Clair, Allen, Specks, Stone.

Analysis and interpretation of data. Clowse, Copland, Hsieh, Chow, Hoffman, Merkel, Spiera, Davis, McCune, St.Clair, Stone.

\section{ROLE OF THE STUDY SPONSOR}

Amgen did not participate in the study design, data collection, data analysis, or writing of this manuscript. Publication was not contingent on the approval of Amgen.

\section{REFERENCES}

1. Park MC, Park YB, Jung SY, Chung IH, Choi KH, Lee SK. Risk of ovarian failure and pregnancy outcome in patients with lupus nephritis treated with intravenous cyclophosphamide pulse therapy. Lupus 2004;13:569-74.
2. Huong DL, Amoura Z, Duhaut P, Sbai A, Costedoat N, Wechsler B, et al. Risk of ovarian failure and fertility after intravenous cyclophosphamide: a study in 84 patients. J Rheumatol 2002;29:2571-6.

3. Te Velde ER, Pearson PL. The variability of female reproductive ageing. Hum Reprod Update 2002;8:141-54.

4. Visser JA, de Jong FH, Laven JS, Themmen AP. Anti-Mullerian hormone: a new marker for ovarian function. Reproduction 2006;131:1-9.

5. Fanchin R, Taieb J, Lozano DH, Ducot B, Frydman R, Bouyer J. High reproducibility of serum anti-Mullerian hormone measurements suggests a multi-staged follicular secretion and strengthens its role in the assessment of ovarian follicular status. Hum Reprod 2005;20:923-7.

6. Van Rooij IA, Broekmans FJ, Scheffer GJ, Looman CW, Habbema JD, de Jong FH, et al. Serum antimullerian hormone levels best reflect the reproductive decline with age in normal women with proven fertility: a longitudinal study. Fertil Steril 2005;83:979-87.

7. Nelson SM, Messow MC, Wallace AM, Fleming R, McConnachie A. Nomogram for the decline in serum antimullerian hormone: a population study of 9,601 infertility patients. Fertil Steril 2011;95:736-41.

8. Sowers MR, Eyvazzadeh AD, McConnell D, Yosef M, Jannausch ML, Zhang D, et al. Anti-mullerian hormone and inhibin $\mathrm{B}$ in the definition of ovarian aging and the menopause transition. J Clin Endocrinol Metab 2008;93:3478-83.

9. Wegener's Granulomatosis Etanercept Trial (WGET) Research Group. Etanercept plus standard therapy for Wegener's granulomatosis. N Engl J Med 2005;352:351-61.

10. Lie Fong S, Lugtenburg PJ, Schipper I, Themmen AP, de Jong FH, Sonneveld P, et al. Anti-mullerian hormone as a marker of ovarian function in women after chemotherapy and radiotherapy for haematological malignancies. Hum Reprod 2008; 23:674-8.

11. Blumenfeld Z, von Wolff M. GnRH-analogues and oral contraceptives for fertility preservation in women during chemotherapy. Hum Reprod Update 2008;14:543-52.

12. Clowse ME, Behera MA, Anders CK, Copland S, Coffman CJ, Leppert PC, et al. Ovarian preservation by $\mathrm{GnRH}$ agonists during chemotherapy: a meta-analysis. J Womens Health 2009;18:311-9.

13. De Groot K, Harper L, Jayne DR, Flores Suarez LF, Gregorini G, Gross WL, et al. Pulse versus daily oral cyclophosphamide for induction of remission in antineutrophil cytoplasmic antibody-associated vasculitis: a randomized trial. Ann Intern Med 2009;150:670-80.

14. Stone JH, Merkel PA, Spiera R, Seo P, Langford CA, Hoffman GS, et al. Rituximab versus cyclophosphamide for ANCAassociated vasculitis. N Engl J Med 2010;363:221-32. 